\title{
Women Silence in the Portrayal of Student Protest against New Criminal Code in Indonesia
}

\author{
W Pujarama ${ }^{1}$, A Bastomi \\ ${ }^{1}$ Universitas Brawijaya, Malang, ${ }^{2}$ Universitas Islam Malang \\ 1'mncprwidya@ub.ac.id
}

\begin{abstract}
Media in some countries appear to preserve gender inequality discourse. Media portrayals form gender mainstreaming that further strengthen stereotype of male/female division and role. This research portrays gender sensitivity in global online news regarding protest against new criminal code in Indonesia. News pictures from 23 headline articles of prominent online media worldwide were selected to investigate how media illustrate protests leading to riots that emerged in the end of September 2019. One of the cause of the protest was a perceived gender inequality, especially about women's right. Alan McKee's textual analysis was performed on the news pictures as the research object. The research focuses on: (1) the scope of framing on male/female protesters; (2) depiction of traditional feminine/masculine characteristics of the protesters seen on frame, and; (3) centrality on female protesters in the picture stories. Results indicate that eventhough some of the new regulations weighs heavily on women, the protest has been depicted as masculine behavior, preserving gender-based stereotypes of women as passive citizens in the society. Notably, female demonstrators were mostly out of frame, as if in silence on the reported protests. As a conclusion, news pictures on online media have not been gender sensitive in illustrating protest in Indonesia.
\end{abstract}

Keywords: Gender Sensitivity, Protest, Textual Analysis, Indonesia

\section{INTRODUCTION}

The distinction between male and female both as biological entities and/or as socialization products has been discussed from a varied perspectives. Liu, Volcic, and Galois summarize that gendered stereotype are language-based, as a result of division in socialization process. For example, the words "activities, accomplishments, or positions" are predominantly expressed by men, and "appearance or relationships" are persistently entitled to women [1]. Other research also shown how in the advertising products, that women are defenceless and decorative being to a man, and the impression had not changed significantly in 13 years period [2].

US media with its global circulation shape the significance of masculinity as the nature of manhood [3]. Regardless the country, following Phillipsen, Goodnow also argues that there are "truths narratives" bound together citizens in forms of cultural myths that evident in the news pictures. Further, it is argued that news picture could "challenge, affirm, or reaffirm" the cultural myths [4]. Inequal gender portrayal of active men and passive women has become one of these cultural myths. 
Speaking about men would not always related to the discussion of gender equality, but also about the gender role distinction. This distinction is called as "prototypical gender role" [5]. Both gender, either male or female are social constructs subjected humankind to think, act, and/or consume as scripted by the major media messages. Traditional characteristics of men, while challenged, are revolved in breadwinning terms, such as power, possession, and achievement. On the contrary, the word femininity revolves arond the look of women. Agresiveness has never been part of women representamen. "Women's anger has been construed as deviant, monstrous or otherwise taboo," [6]. These media messages forms the audiences' world view [7]. Another example, in 1990s television shows, speaking role once had been dominated by men (61\% in 1992, and 63\% in 1995), although in 1995 female main actor rised into $43 \%$, (from $18 \%$ in 1992). This made a misleading logic behind cosmetics and fashion consumption for both men and women, which stiffen the sexual difference of male and female as a gender. Explained further, Gauntlett also argues that as seen in media, a "culture of men" dominates the top level management both in business and organisations [7].

The categorization and the descriptions of the world are determined by the language use, and reciprocated in the nonverbal elements of communication, including how gender is divided worldwide via pictures of online news. On her book chapter, Ross argues that online news last only eight seconds in average, making journalists do interpret more than do report reality [8]. Objectivity of the news articles were naturally unchallenged if photographs are ascribed. News pictures, as other type of photographs serves as "a belieavable proof that is is a tangible thing" [4].

From the perspective of visual communication, photographs serves as the vehicle of narrative, or as stated by Barbatsis as "storytelling experience." Thus, pictorial expressions shows simulation or "iconic" symbol of reality while showing objectiveness and naturalness [4]. Apart from the objective practice of news reporting, online media tend to overlook gender, especially when reporting violence or riots. A uniformed style appeared on the media, situating men as active catalysts of change. A routine feature included in most of reportage of protests takes forms of clashes involving officials and the protesters. Adult male continues predominance in the reported scenes. These phenomena evince that dramaturgical riots broke out in Indonesia had been prevailed on by men, reported by men, and heralded by men. Consequently, a gender sensitivity becomes an issue in protest coverages.

Assessing news pictures as semiotic resources independent from the printed words is not a new approach. Abousnnouga and Machin scrutinised war monuments and the discourse of nationalism using semiotics of their collected photographs, arguing that both religion and cultural values reinforce the virility of war [9]. In journalism field, picture of women are frequently put as an 'eye candy" accompanying the content of the news. A content analysis research on the online news articles showed that females had been emerged more in news pictures than in the text, when being compared to males [10]. The result were contrasting this research argument, that even in news pictures, male domination are still veridical.

\section{RESEARCH METHOD}

This is a qualitative research employing textual analysis as a methodology. Textual analysis seeks an understanding through sense-making in a specific cultural frameworks [11]. The researchers directed this study to understand how student protest in Indonesia had been told in pictures of headline articles for international readers. This research focuses on: (1) the proportions of male/female protesters seen on frame; (2) the depiction of traditional feminine/masculine characteristics of the protesters seen on frame, and; (3) the centrality on 
female protesters in the picture stories. The researchers coded the picture and filled the qualitative coding sheets to seek for patterns based on the research focus.

As many as 46 news pictures from 23 headline articles were investigated as the research objects, as seen in Table 1. The data collection was undertaken with two steps. Firstly, "student protest," "Indonesia," and " 2019 " were selected as keywords to seek for English written articles in online media, with the help of a search engine to narrow the number of the most read articles worlwide about the 2019 student protest against new criminal code in Indonesia. Secondly, articles that was not a headline and not in English were being eliminated. From this purposive sampling technique, 23 articles published between 23 to 30 September 2019 from 18 different media institutions which are based across 4 continents were obtained, as seen in Picture 1 . below.

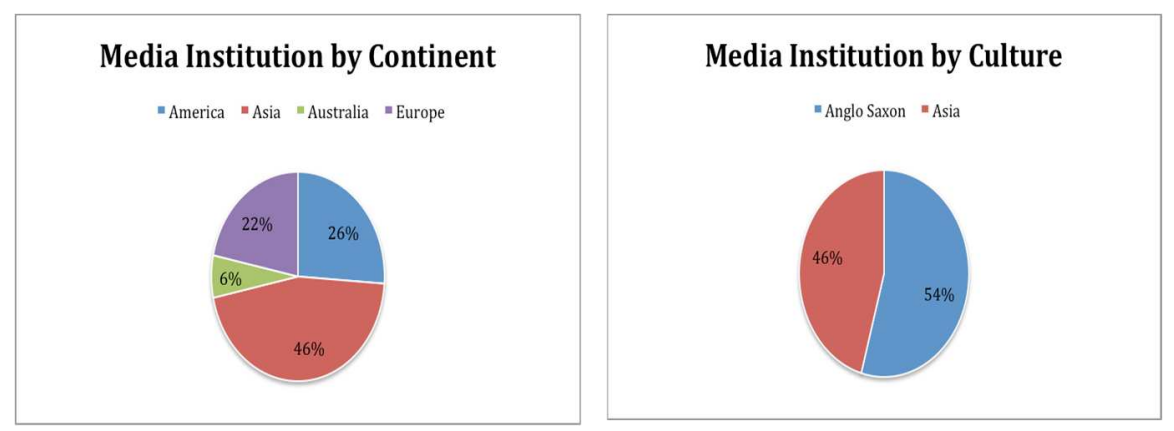

PICTURE 1. The distribution of region and cultural perspective of selected news articles

All English news articles were written by two type of culture or perspective, of Anglo-Saxon and Asian one. The data, then, were analyzed to seek a Western portrayal of cultural-based gender, particularly in an episode of protest that lead to riots in Indonesia.

\section{RESULTS AND DISCUSSION}

This section will illustrate the result of the study. Initially, there were 50 news pictures catalogued by the researchers, but four softfiles were damaged in the process. The summary of institution, date published, the number of news pictures, and the country of origin were shown in Table 1.

Three major themes were emerged from the text analysed. Firstly, how the news pictures serve as a dramaturgical theater of protest patterning Full Shots (FS) of male anarchies. Secondly, a structured logic that put female protesters and/or officials in a guarded position resembling the war situation where potential clash emerged during the protest, had habituated the readers to portray protest situations as a male dominated activity. Thirdly, close ups of female protesters were emerging in agreement with the content of the protest, which some were about women and inequality. Furthermore, the news pictures were still preserving the old school claim that picture of women in news serves as an eye candy. These results endorse a confining set of discourse of female activism, yet supporting the view of protest as a masculine trait from media institutions in America, Asia, Australia, and Europe.

\subsection{The Protest as a Collective Spectatorship}

News picture is assumed to be factual as it records an instant moment with certitude. 
However, it is evident that news pictures being studied, coining Goodnow [5], have reaffirmed the cultural myth of masculinity in protest situation in Indonesia. It appeared as though male protesters are megalomania detached from the expostulatory messages. The texts portray the different gender performance of male and female in the Indonesian student protest 2019. Male protesters were dominating the news pictures both in quantity and role taking. Active contributions such as orations were mostly situated being given by male protesters. In addition, male protesters were also serve as borders in protest, symbolizing the guardian duty.

TABLE 1. The number of headline news articles selected as research objects

\begin{tabular}{|c|c|c|c|c|c|c|c|}
\hline No & Institution & Country & $\begin{array}{c}\text { Number } \\
\text { of } \\
\text { Picture } \\
\text { (s) }\end{array}$ & No & Institution & Country & $\begin{array}{c}\text { Number } \\
\text { of } \\
\text { Picture } \\
\text { (s) }\end{array}$ \\
\hline 1 & The Guardian & UK & 1 & 13 & DW & Germany & 2 \\
\hline 2 & The Guardian & UK & 1 & 14 & $\mathrm{SMH}$ & Australia & 1 \\
\hline 3 & VOA & US & 4 & 15 & SCMP & Hongkong & 3 \\
\hline 4 & $\mathrm{BBC}$ & UK & 3 & 16 & The Jakarta Post & Indonesia & 2 \\
\hline 5 & $\begin{array}{l}\text { New York } \\
\text { Times }\end{array}$ & US & 2 & 17 & $\begin{array}{l}\text { Channel News } \\
\text { Asia }\end{array}$ & Singapore & 4 \\
\hline 6 & $\mathrm{CNN}$ & US & 3 & 18 & Independent UK & UK & 1 \\
\hline 7 & Aljazeera & Qatar & 2 & 19 & Irish Times & Irlandia & 1 \\
\hline 8 & ABC Australia & Australia & 2 & 20 & Japan Times & Japan & 1 \\
\hline 9 & StraitsTimes & Singapore & 2 & 21 & $\begin{array}{l}\text { The Star } \\
\text { Malaysia }\end{array}$ & Malaysia & 1 \\
\hline 10 & Washington Post & US & 1 & 22 & Tempo & Indonesia & 6 \\
\hline 11 & Reuters & UK & 1 & 23 & HRW & US & 1 \\
\hline 12 & OANN & US & 1 & & Total & & 46 \\
\hline
\end{tabular}

Most of the media portrayals place confrontation exhibited by men, both from the protesters and officials. It is also signified that male protesters have higher ability of risk taking. This seen from the Picture 1., where a male protester in different pictures tried to fend off water canons from the officials. Chaotic scenes were captured on the news pictures, which were dominated by male protesters in frames. No female protesters were able to be identified on the front line of the riot situation.

Some of the male protesters also framed fighting back the officials by throwing a trash bag, as shown in Picture 1. The pictures were conspicuously taken with low shutter speed, creating a unique suspenseful situation portraying a man of action. Notably, the male protesters symbolic identity as students were bold, in the form of the university jacket, or jaket almamater.

\subsection{Power, Masculinity, and Violence}

The news pictures depict male protesters as the agent of change in three different ways. Firstly, less than $10 \%$ out of 46 pictures situate female protesters in frame, seemingly intending to highlight the demonstration properties and the messages, but not the female protesters as active participants. From the gesture of the protesters, it is inferred that male protesters took an 
effort to barricade female protesters from the potential violence, making male protesters on the front line of potential contact with the police officers, and vice versa, only male police officers were in frame in the reported news pictures.

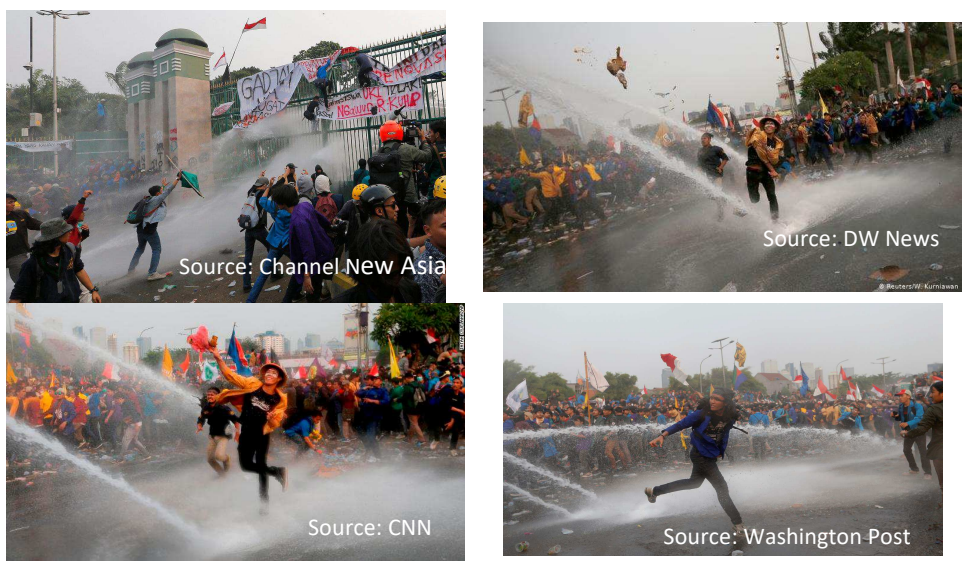

PICTURE 1. Male Protesters Defending the Self from the Water Canons. Source: ChannelNewsAsia [12], DW News [13], CNN [14], the Washingtonpost [15]

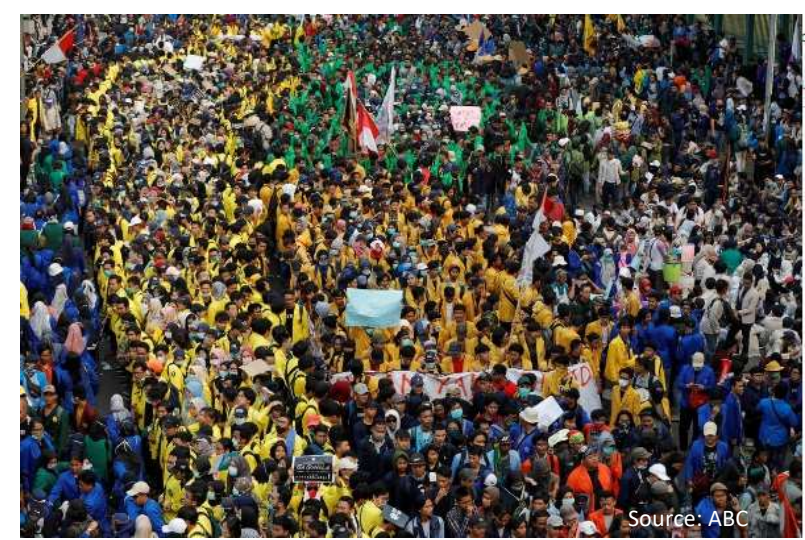

PICTURE 2. The Structured Barricade of Male and Female Protesters. Source: (ABC) [16].

The male protesters exhibit their dominant role in the demonstration that lead to violence and riots. Apart from barricaded female protesters situated in the centre of the site, female protesters were only depicted on the pheripery of the site, holding banners and other properties.

As stated above, jaket almamater has become a prominent symbol of student protests. In relations to the violence acts captured on the news pictures, the protesters could be categorized into two type: of students with visible uniforms, and of non-student protesters who were not wearing their jaket almamater. The data show that lesser male with jaket almamater in frame, the actions portrayed on the news pictures are more brutal accordingly. Although the pictures are consistently being dominated by acts of male protesters, indicating that protest or riots are male-dominated [9]. 


\subsection{Close Ups of Female Protesters}

Traditional femininity resembled in close ups of make ups of female protesters, including the painted fingernails. Furthermore, the protest were highlighting close ups of female protesters more than the male ones. Papers, white boards, markers, and flags were in framed properties held by female protesters, signifying that female protesters' voice is mediated, while the male protesters were being portrayed as active agents.

It is also worth noting that the news pictures put female protesters as the main object of the camera, while male protesters were captured as the background, being portrayed as busy and serious.

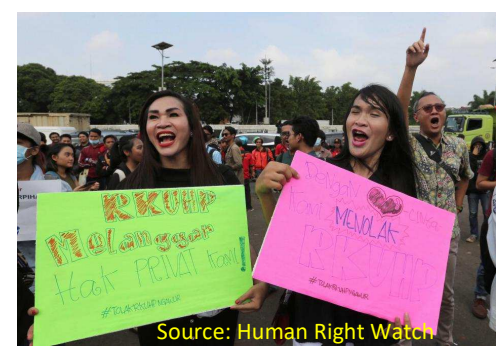

PICTURE 3. The Eye Candy (HumanRightWatch) [17]

The picture above supports what Jia, Landsdall-Welfare, Sudhahar, Carter, and Cristianini's finding that in some point, the female appearance serves as an "eye candy" [10]. Although the framed female were gender crossovers, but the aesthetics of framing and make ups were made more dominant in comparison to the messages contained on the protest properties seized by the protesters.

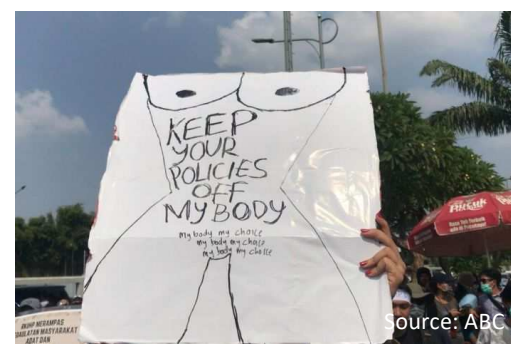

PICTURE 4. The Bare Poster (ABC) [16]

Exhibited in the Picture 4, a female protester, marked by painted fingernails held up a straighforward poster of a naked female body with writings inside the body: "KEEP YOUR POLICIES OF MY BODY - my body my choice - my body my choice - my body my choice." This picture intensifies a premise that properties interposed itself between female protesters and the camera depicting the situation. Thus female protesters were more in silence than the male ones. Rage were captured differently from female protesters, supporting the illicit women temper [6].

The online news pictures have sustained gender inequality, preserving the idea of men as the dominant and active agents of change [1] in a non verbal way. It is evident in how the news pictures frames markedly more male than female protesters. Two different scopes of actions emerged indicating the impression of forceful men and weak women, as previously 
argued by Kang [2] and referred as "prototypical gender role" [5]. Appearances were mostly pictured from female protesters whereas activities or actions were taken from the male ones. Thus, anarchy correlates with men and expression corresponds with women, in the context of the 2019 student protest against new criminal code. Culturaly speaking, riots are closely related to men, as wars were in the past [9]. This has also been evident in this research, strengthening gender stereotyope [4] in Anglo-saxon culture. Global media were reporting the event in a homogeneous fashion, including the ones from the US [3].

From the viewpoints of the photographer, it could be derived that gender are a type of performance both in the manner of the image capture and in the sense of the gestures of the protesters on frames, reaffirming the culture of men [7] [4]. As established by Ross, that pictures are iconic [8], this research found that gender performance and framing have become typical for the international readers.

A mislead message would defy the urgency of the expected responses. Not only that female protesters were never situated in the central position of the picture frames, the male protesters were also experiencing uniformed framing from the photo journalists, as seen in the news pictures. The uniform nonverbal messages sent from the news pictures analyzed above, could potentially bend the main issues and consequenty demands of the protest. This make student protests in Indonesia are portrayed as a far from insighful conducts, especially when it further lead to riots.

\section{CONCLUSIONS}

News pictures, as discussed above are not merely the complimentary element of news texts. A cultural portrayal both as a new information and/or a preserved patrilineal belief that maintains the gender equality are evident on this research. This reseach found that the framing patterns of the news pictures exhibits gender performance in the scope of full shots of male anarchies, female protesters guarded by male barricade, and only a few close ups of female protesters. Protest situation, leading to riots were depicted as a male dominated activity. Thus the centrality of news pictures narratives are belong to the male protesters, that further suggesting the taciturnity of the female ones.

It is concluded that the imbalance portrayals support the research argument that online media aiming international audiences and their journalism practices have not been fully gender sensitive, especially in the reportage on student protest against new criminal code in Indonesia year 2019 .

\section{REFERENCES}

[1] S. Liu, Z. Volcic, and C. Gallois, Introducing intercultural communication: Global cultures and contexts, 2nd ed. London: Sage Publishing, 2015.

[2] M. Kang, “The Portrayal of Women's Images in Magazine Advertisements: Goffman's Gender Analysis Revisited,” Sex Roles, vol. 37, no. 11-12, pp. 979-996, 1997.

[3] C. Strong, The Handbook of Gender, Sex and Media, vol. 14, no. 2. 2014.

[4] K. Smith, S. Moriarty, G. Barbatsis, and K. Kenney, Eds., Using narative. .

[5] A. Furnham, T. Mak, and L. Tanidjojo, "An Asian perspective on the portrayal of men and women in television advertisements: Studies from Hong Kong and Indonesian television," J. Appl. Soc. Psychol., vol. 30, no. 11, pp. 2341-2364, 2000.

[6] J. B. Kay, "Introduction: anger, media, and feminism: the gender politics of mediated rage,” Fem. Media Stud., vol. 19, no. 4, pp. 591-615, 2019. 
[7] D. Gauntlett, Media, Gender and Identity. 2008.

[8] T. Krijnen, C. Alvares, and S. van Bauwel, Gendered transformations: Theory and practices on gender and media. 2010.

[9] P. Eckert, The Semiotic Landscape. 2018.

[10] S. Jia, T. Lansdall-Welfare, S. Sudhahar, C. Carter, and N. Cristianini, "Women are seen more than heard in online newspapers," PLoS One, vol. 11, no. 2, pp. 1-12, 2016.

[11] A. Mckee, Textual Analysis, 1st ed. London: Sage Publishing, 2003.

[12] ChannelNewsAsia, "Indonesia police fire tear gas as protesters rally against graft law, Bill banning pre-marital sex," Photo, 2019. [Online]. Available: https://www.channelnewsasia.com/news/asia/indonesian-police-fire-tear-gas-sex-lawprotesters-11938268. [Accessed: 26-Nov-2019].

[13] DeutscheWelle, "Indonesian cities rocked by third day of student demonstrations," 2019.

[14] J. Hollingsworth, "Indonesian police fire tear gas, water cannons, as students protest law that would criminalize extramarital sex," 2019. [Online]. Available: https://edition.cnn.com/2019/09/25/asia/indonesia-protests-criminal-code-intlhnk/index.html. [Accessed: 26-Nov-2019].

[15] TheWashingtonPost, "Indonesia students rally against changes to corruption laws," 2019. [Online]. Available: https://www.washingtonpost.com/world/asia_pacific/indonesia-students-rally-againstchanges-to-corruption-law/2019/09/24/e860a64a-deb5-11e9-be7f4cc85017c36f_story.html. [Accessed: 26-Nov-2019].

[16] ABC, "Indonesia protests over new criminal code see students defy police firing tear gas and water cannon," 2019. [Online]. Available: https://www.abc.net.au/news/201909-25/thousands-protest-against-new-criminal-code-in-indonesia/11545214.

[Accessed: 21-Nov-2019].

[17] A. Harsono, "Indonesia's President Urges Delay on Criminal Code Vote," 2019. [Online]. Available: https://www.hrw.org/news/2019/09/23/indonesias-presidenturges-delay-criminal-code-vote\%0A. [Accessed: 21-Nov-2019]. 